\title{
Autonomic response to exercise as measured by cardio- vascular variability
}

\author{
C C Grant (MSc) $)^{1}$
}

J A Ker (MB ChB, MMed (Int), MD) ${ }^{2}$

${ }^{1}$ Section Sports Medicine, University of Pretoria

${ }^{2}$ Department of Internal Medicine, University of Pretoria

\begin{abstract}
Motivation. There is growing interest in the use of cardiovascular variability indicators as measures of autonomic activity, even though reported results are not always comparable or as expected. This review aims to determine the consistency of results reported on the autonomic response to physical exercise as measured by heart rate variability, blood pressure variability and baroreceptor sensitivity.

Method. An Ovid MEDLINE Database search for the period 1950 - March 2008 produced 46 articles for review. The published articles that evaluate the effect of exercise on the autonomic nervous system (ANS) are summarised in three categories: the response of the ANS during a bout of exercise, directly after exercise (recovery measurements), and after a long-term exercise programme.

Results. Articles on the effect of training on the ANS as measured by cardiovascular variability indicators show increased variability, decreased variability, and no change in variability.

Conclusion. Findings in this review emphasise that standardisation and refinement of these measuring tools are essential to produce results that can be repeated and used as reference. Standardisation is essential as these measurements are increasingly employed in studies regarding investigations of central autonomic regulation, those exploring the link between psychological pro cesses and physiological functioning, and those indicating ANS activity in response to exercise, training and overtraining. This review shows that important aspects are inter-individual differences, duration and intensity of the exercise programme, and choice and specific implementation of variability analysis techniques.
\end{abstract}

\section{CORRESPONDENCE:}

\section{Mrs C C Grant}

Section Sports Medicine

University of Pretoria

Tel: 27123624496

Fax: 27123623369

E-mail: Rina.Grant@up.ac.za

\section{Introduction}

Heart rate variability (HRV), blood pressure variability (BPV) and baroreceptor sensitivity (BRS) are often used as measures of autonomic activity, even though reported results are not always comparable or as expected. It is known that endurance athletes have lower average resting heart rates than non-exercising individuals. ${ }^{33,50}$ However, other exercise-induced autonomic influences on cardiac control are far more controversial.

Autonomic control via sympathetic and parasympathetic modulation of the heart has been assessed by power spectral analysis of $\mathrm{HRV}^{1,7,33,41,46,48,50}$ and BPV. ${ }^{44,52}$ Different frequency peaks reflect specific physiological stimuli and it is possible to estimate the involvement of the autonomic nervous system (ANS) influence and balance in heart rate (HR) regulation. ${ }^{1,2,6}$ With power spectral analysis of $\mathrm{HR}$, two characteristic peaks between $0.04 \mathrm{~Hz}$ and $0.15 \mathrm{~Hz}(\mathrm{~A})$ and between $0.15 \mathrm{~Hz}$ and $0.5 \mathrm{~Hz}(\mathrm{~B})$ are used to quantify the autonomic balance in terms of the low-frequency (LF)/ high-frequency (HF) ratio. ${ }^{1,6,48}$ Peak $A$ is found in the region of Mayer waves $(0.1 \mathrm{~Hz})$ and is situated in the so-called LF area. It appears to be linked to the combined activities of the sympathetic and parasympathetic branches of the ANS. Peak B is synchronous with respiration, reflects vagal activity, is situated in the so-called HF area

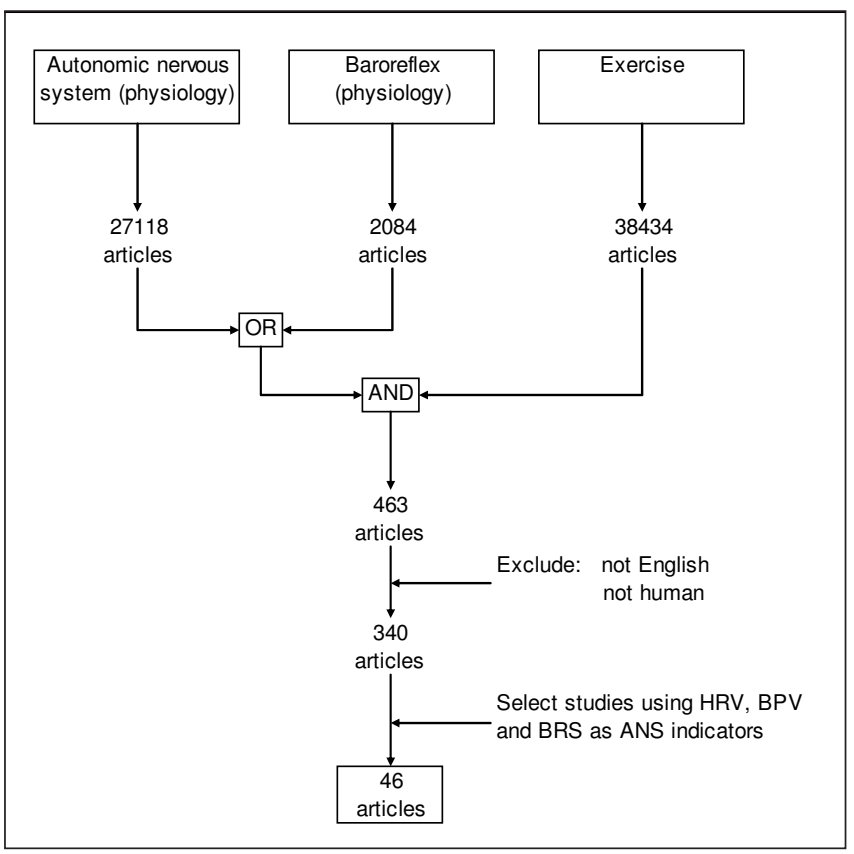

Fig. 1. Summary of the Ovid MEDLINE Database search. 


\section{TABLE I. Articles on the response of the ANS measured during a bout of exercise}

\begin{tabular}{|c|c|c|c|}
\hline Reference number & Author/s & Title & Cardiovascular variability indicator \\
\hline 43 & Sandercock et al. & $\begin{array}{l}\text { The use of HRV measures to } \\
\text { assess autonomic control } \\
\text { during exercise }\end{array}$ & $\begin{array}{l}\text { Results from spectral analysis } \\
\text { of HRV not as expected; more } \\
\text { research needed: word of caution }\end{array}$ \\
\hline 5 & Banach et al. & $\begin{array}{l}\text { HRV during incremental cycling } \\
\text { exercise in healthy, untrained } \\
\text { young men }\end{array}$ & $\begin{array}{l}\text { Spectral and time domain } \\
\text { analysis of HRV } \\
\downarrow \text { SDNN, RMSSD } \\
\downarrow \text { LF, HF; LF/HF } \\
\downarrow \text { Ptot }\end{array}$ \\
\hline 16 & Freeman et al. & $\begin{array}{l}\text { ANS interaction with the CV } \\
\text { system during exercise }\end{array}$ & $\begin{array}{l}\text { Encourage the use of HRV at } \\
\text { rest and during exercise }\end{array}$ \\
\hline 14 & Eryonucu et al. & $\begin{array}{l}\text { The effect of ANS activity on } \\
\text { exaggerated blood pressure } \\
\text { response to exercise: evaluation by HRV }\end{array}$ & $\begin{array}{l}\text { Used spectral analysis of HRV in a } \\
\text { comparative study }\end{array}$ \\
\hline 29 & Lucini et al. & $\begin{array}{l}\text { Analysis of initial autonomic } \\
\text { adjustments to moderate } \\
\text { exercise in humans }\end{array}$ & $\begin{array}{l}\text { Spectral analysis of HRV } \\
\uparrow L F \text { suggest } \uparrow S N S \\
\downarrow H F \text { suggest } \downarrow P N S \\
\leftrightarrow \text { and } \uparrow L F \text { of BPV }\end{array}$ \\
\hline 42 & Saito and Nakamura & $\begin{array}{l}\text { Cardiac autonomic control and } \\
\text { muscle sympathetic nerve } \\
\text { activity during dynamic exercise }\end{array}$ & $\begin{array}{l}\text { Spectral analysis of HRV } \\
\downarrow \text { LF power, } \downarrow \text { HF power, } \\
\leftrightarrow \text { total power } \\
\uparrow L F / H F: \text { SNS } \uparrow \\
\downarrow \text { HF/Ptot : PNS } \downarrow\end{array}$ \\
\hline 26 & Kamath et al. & $\begin{array}{l}\text { Effects of steady-state exercise } \\
\text { on the power spectrum of HRV }\end{array}$ & $\begin{array}{l}\text { Spectral analysis of HRV } \\
\downarrow L F, \downarrow H F, \text { SNS } \downarrow, \text { PNS } \downarrow\end{array}$ \\
\hline 3 & Arai et al. & $\begin{array}{l}\text { Modulation of cardiac autonomic } \\
\text { activity during and immediately } \\
\text { after exercise }\end{array}$ & $\begin{array}{l}\text { Spectral analysis of HRV } \\
\downarrow H F \\
\downarrow L F\end{array}$ \\
\hline 51 & Yamamoto et al. & $\begin{array}{l}\text { Autonomic control of HR during } \\
\text { exercise studied by HRV } \\
\text { spectral analysis }\end{array}$ & $\begin{array}{l}\text { Spectral analysis of HRV } \\
\downarrow \text { HF: PNS } \downarrow \\
\uparrow \text { and } \leftrightarrow \text { LF/HF: } \uparrow \text { and } \leftrightarrow \text { SNS }\end{array}$ \\
\hline 37 & Perini and Veicsteinas & $\begin{array}{l}\text { HRV and autonomic activity at rest } \\
\text { and during exercise in various } \\
\text { physiological conditions }\end{array}$ & $\begin{array}{l}\text { Spectral analysis of HRV } \\
\text { No change in HF and LF } \\
\text { power during increased loads } \\
\leftrightarrow H F, \leftrightarrow L F\end{array}$ \\
\hline
\end{tabular}

$\mathrm{LF}=$ low frequency; $\mathrm{HFR}=$ high frequency; SDN = standard deviation of all intervals; Ptot = total frequency power; pNN50 = percentage of successive interval differences greater than $50 \mathrm{~ms}$; SNS = sympathetic nervous system; PNS = parasympathetic nervous system; SAP = systolic arterial pressure

and also gives an indication of respiratory sinus arrhythmia (RSA). ${ }^{1,48}$ During measurement of systolic BPV the LF peak corresponds with sympathetic activity while the HF peak is determined by mechanical effects of respiration on intrathoracic pressure and cardiac filling. ${ }^{44,52}$ The variability in blood pressure and identification of the corresponding physiological stimuli are difficult to identify. Indications are that the very low frequencies $(\leq 0.04 \mathrm{~Hz})$ are influenced by vascular tone, endothelium factors and thermoregulation, and the LF peak $(0.07$ $-0.15 \mathrm{~Hz}$ ) relates to sympathetic activity and represents vasomotor tone. ${ }^{2}$ BRS reflects mainly vagal modulation of the HR by the arterial baroreceptors and the magnitude of response in heart beat interval to a change in blood pressure $(\mathrm{ms} / \mathrm{mmHg}){ }^{6}$

Physical exercise requires rapid and complex physiological adaptation, particularly by the ANS. Exercise programmes require changes in the neural cardiovascular and ANS control that are unique to the person and his/her surroundings. This review aims to determine the consistency of results reported on the autonomic response to physical exercise as measured by HRV, BPV and BRS.

\section{Method}

An Ovid MEDLINE Database search was conducted for the period 1950 - March 2008 (Fig. 1). The term 'ANS (physiology)' produced 27 118 articles, and 'baroreflex (physiology)' 2084 articles. When link- ing the results with the term 'exercise' (38 434 articles) and then limiting the results to 'humans and English', 340 references were found. Only articles that used HRV (determined by time-domain analysis, Poincaré analysis and/or frequency-domain analysis), non-invasive $\mathrm{BPV}$ and BRS as indicators of autonomic function were selected, yielding 46 articles.

\section{Results}

Published articles on the effect of exercise on the ANS as measured by HRV and BPV are summarised in three categories: the response of the ANS measured during a bout of exercise, $3,5,14,16,26,29,37,42,43,51$ and directly after a bout of exercise (recovery measurements), $3,9,22-$ $24,28,40,49$ and the long-term effect of regular exercise on the ANS. $4,8,10-13,15,17,18,19-21,25,27,30-32,34-36,38,39,45,47$

The results of 10 articles on ANS response measured during exercise are shown in Table I. Some authors expressed concern about the measurement of spectral analysis of HRV during exercise, while others reported increases $(\uparrow)$, decreases $(\downarrow)$ and no changes in variability indicators $(\leftrightarrow)$ of sympathetic (SNS) and parasympathetic (PNS) influence.

Table II shows results of 10 articles on the response of the ANS measured after a bout of exercise (recovery measurements). Comments found were based on time domain, spectral and coarse- 
TABLE II. Articles on the response of the ANS measured directly after a bout of exercise (recovery measurements)

\begin{tabular}{|c|c|c|c|}
\hline Reference number & Author/s & Title & Cardiovascular variability indicator \\
\hline 24 & Heffernan et al. & $\begin{array}{l}\text { Cardiac autonomic modulation } \\
\text { during recovery from acute } \\
\text { endurance v. resistance exercise }\end{array}$ & $\begin{array}{l}\text { Spectral analysis of HRV } \\
\text { After endurance: } \\
\leftrightarrow \text { total power, } \uparrow \mathrm{LF} / \mathrm{HF} \text {, } \\
\text { After resistance: } \\
\downarrow \text { total power of HRV, } \\
\uparrow L F / H F\end{array}$ \\
\hline 49 & Terziotti et al. & $\begin{array}{l}\text { Post-exercise recovery of autonomic } \\
\text { cardiovascular control: a study by } \\
\text { spectrum and cross-spectrum analysis } \\
\text { in humans }\end{array}$ & $\begin{array}{l}\text { Spectral analysis of HRV and BPV } \\
\uparrow L F \text { of systolic blood pressure } \\
\downarrow H F \text { activity of heart rate } \downarrow \text { decreased BRS }\end{array}$ \\
\hline 22 & Hayashi et al. & $\begin{array}{l}\text { Cardiac autonomic regulation after } \\
\text { moderate and exhaustive exercises }\end{array}$ & $\begin{array}{l}\text { Coarse-graining spectral analysis of HRV } \\
\downarrow \text { HF } \\
\uparrow L F / H F\end{array}$ \\
\hline 40 & Raczak et al. & $\begin{array}{l}\text { Cardiovagal response to acute } \\
\text { mild exercise in young healthy subjects }\end{array}$ & $\begin{array}{l}\text { Time domain and spectral analysis } \\
\text { of HRV and BRS } \\
\uparrow \text { SDNN } \\
\leftrightarrow \text { LF and HF } \\
\downarrow B R S\end{array}$ \\
\hline 26 & Kamath et al. & $\begin{array}{l}\text { Effects of steady state exercise } \\
\text { on the power spectrum of HRV }\end{array}$ & $\begin{array}{l}\text { Spectral analysis of HRV } \\
\text { 个LF activity }\end{array}$ \\
\hline 23 & Heffernan & $\begin{array}{l}\text { Arterial stiffness and baroreflex } \\
\text { sensitivity following bouts of aerobic } \\
\text { and resistance exercise }\end{array}$ & $\begin{array}{l}\text { BRS via the sequence technique } \\
\downarrow \text { BRS after resistance and aerobic exercise. } \\
\text { Greater reduction after resistance }\end{array}$ \\
\hline 9 & Brown and Brown & $\begin{array}{l}\text { Resting and post-exercise cardiac } \\
\text { autonomic control in trained } \\
\text { master athletes }\end{array}$ & $\begin{array}{l}\text { Time domain and spectral analysis of HRV } \\
\downarrow \text { SDRR , } \downarrow \text { total power, } \downarrow \text { HF. } \\
\leftrightarrow \text { LF }\end{array}$ \\
\hline 28 & Lucini et al. & $\begin{array}{l}\text { Selective reductions of cardiac } \\
\text { autonomic responses to light bicycle } \\
\text { exercise with aging in healthy humans }\end{array}$ & $\begin{array}{l}\text { Spectral analysis of HRV and BPV } \\
\text { HRV decreases with age } \\
\text { BRS via sequence technique }\end{array}$ \\
\hline 15 & Figueroa et al. & $\begin{array}{l}\text { Endurance training improves } \\
\text { post-exercise cardiac autonomic } \\
\text { modulation in obese women } \\
\text { with and without type } 2 \text { diabetes }\end{array}$ & $\begin{array}{l}\text { Spectral analysis of HRV } \\
\text { BRS via sequence technique } \\
\uparrow H F, \text { LF, BRS }\end{array}$ \\
\hline 3 & Arai et al. & $\begin{array}{l}\text { Modulation of cardiac autonomic } \\
\text { activity during and immediately } \\
\text { after exercise }\end{array}$ & $\begin{array}{l}\text { Spectral analysis of HRV } \\
\downarrow H F, \downarrow L F\end{array}$ \\
\hline
\end{tabular}

$\mathrm{LF}=$ low frequency; HFR = high frequency; SDN = standard deviation of all intervals; Ptot = total frequency power; pNN50= percentage of successive interval differences greater than $50 \mathrm{~ms}$; SNS = sympathetic nervous system; PNS = parasympathetic nervous system; SAP $=$ systolic arterial pressure .

graining analysis of HRV and BRS via the sequence technique and spectral analysis of BPV.

Table III summarises findings on the long-term effect of regular exercise on the ANS. Some of the different techniques used to estimate cardiovascular variability were time domain and spectral analysis of HRV, BRS via sequence technique and the alpha index, spectral analysis of BRS and also BRS via the slope of the baroreflex sequences and transfer function gain.

\section{Discussion}

Articles published on cardiovascular variability measured during exercise concluded that the interpretation of variability measurements is difficult because indicators reflecting sympathovagal interactions at rest do not behave as expected during exercise and that the increased respiratory effort had a confounding effect on HF bands. ${ }^{43}$ It is also suggested that the presence of cross-sectional differences between HRV in athletes and non-athletes should be noted and that one should not use HRV data to determine autonomic control during exercise. Doubt was expressed on the applicability of the HRV power-spectrum analysis, with its present interpretation, to assess the sympathovagal interaction during exercise. ${ }^{5}$ However, other authors encouraged the use of HRV components at rest and during exercise as prognostic indicators, but called for the refinement of exercise measurements. ${ }^{16}$ Eryonucu et al. used HRV as an indicator of ANS activity before, during and after exercise in a comparative study. ${ }^{14}$ Two other studies reported increased sympathetic influence (measured by LF and LF/HF) on autonomic cardiac control during graded exercise, ${ }^{29,42}$ including increased, peripheral, vascular sympathetic activation at $30 \%$ of maximum exercise in the study by Saito and Nakamura. ${ }^{42}$ These results were in direct conflict with studies indicating significant suppression of both SNS and PNS autonomic cardiac control during graded exercise measured by the LF and HF of the power spectrum of HRV. ${ }^{3,26}$ In 1991 Yamamoto et al. ${ }^{51}$ reported decreased PNS activity (HF) and unchanged SNS activity (LF/HF) up to $100 \%$ of the predetermined ventilatory threshold ( $\left.T_{\text {vent }}\right)$, with an abrupt increase in SNS activity (LF/HF) only at $100 \%$ Tvent. Perini and Veicsteinas ${ }^{37}$ concluded that changes in HF and LF power and in LF/HF observed during exercise do not reflect the decrease in vagal activity and the activation of the SNS at increasing loads; neither did fitness level, age and hypoxia have any influence. However, exercising at medium-high intensities in the supine position did produce measurable increased power in LF.

Cardiovascular variability measured during recovery from a single bout of endurance exercise indicated that the total power of HRV 


\section{Reference number}

15

47

4

31

\section{Author/s}

Figueroa et al.

Spierer et al.

Aubert et al.

Martinelli et al.

Sharma et al.

Perini and

Veicsteinas

Buchheit and

Gindre

Raczak et al

Okazaki et al.

Melo et al.

Goldsmith et al.

\section{Goldsmith et al.}

Kiviniemi et al.

Cooke et al.

Costes et al.

Monahan et al.

Carter et al.

lellamo et al

Bowman et al.

\section{Name}

Endurance training improves post-exercise cardiac autonomic modulation in obese women with and without type 2 diabetes Exercise training improves cardiovascular and autonomic profiles in HIV

Low-dose exercise does not influence cardiac autonomic control in healthy sedentary men aged $55-75$ years

$\mathrm{HRV}$ in athletes and non-athletes at rest and during head-up tilt

Short term physical training alters cardiovascular autonomic response amplitude and latencies

HRV and autonomic activity at rest and during exercise in various physiological conditions

Cardiac parasympathetic regulation: respective associations with cardiorespiratory fitness and training load

Long-term exercise training improves ANS profile in professional runners

Dose-response relationship of endurance training for autonomic circulatory control in healthy seniors

Effects of age and physical activity on the autonomic control of heart rate in healthy men

Exercise and autonomic function

Physical fitness as a determinant of vagal modulation

Cardiac vagal outflow after aerobic training by analysis of high-frequeny oscillation of the R-R interval

Effects of training on $\mathrm{CV}$ and sympathetic responses to Valsalva's maneuver

Influence of exercise training on cardiac BRS in patients with COPD

Regular aerobic exercise modulates age-associated declines in cardiovagal baroreflex sensitivity in healthy men

Effect of endurance training on autonomic control of heart rate - review

Conversion from vagal to sympathetic predominance with strenuous training in high-performance athletes

Effects of aerobic exercise training and yoga on the baroreflex in healthy elderly persons
Cardiovascular

variability indicator

Spectral analysis of HRV

$B R S$ via sequence technique

$\leftrightarrow \mathrm{HRV}$ and BRS: no baseline changes

Spectral analysis of HRV

BRS via alpha index

$\uparrow$ BRS increased

$\uparrow \mathrm{HF}$

$\downarrow$ LF/HF

Spectral analysis of HRV $\leftrightarrow$ LF, HF, LF/HF

Spectral analysis of HRV $\uparrow$ SDNN

$\leftrightarrow \mathrm{LF}, \mathrm{HF}: \mathrm{SNS} / \mathrm{PNS} \leftrightarrow$

Time domain and spectral analysis of HRV

$\leftrightarrow \mathrm{HRV}$ indicators

Spectral analysis of HRV

Fitness level has no influence

Time domain and spectral analysis of HRV

$\uparrow H F$, RMSSD, PNN 50

Time domain and spectral analysis of HRV, spectral analysis of BRS

$\uparrow S D N N$, pNN50, RMSSD,

个Total power and LF

个BRS

Spectral analysis of HRV

$B R S$ via transfer function gain

$\uparrow$ SDRR, LF, HF

个BRS

Time domain and spectral analysis of HRV

个RMSSD

$\downarrow H R$

Review

$\uparrow$ SNS activity

$\downarrow P N S$ activity

Spectral analysis of HRV 个HF

Spectral analysis of HRV $\uparrow H F$

Time domain analysis of HRV, BRS $\uparrow S D R R$

个BRS

$B R S$ via the slope of the baroreflex sequences between systolic blood pressure changes $\uparrow \mathrm{BRS}$

$B R S$ via linear regression between $\mathrm{BP}$ en RR intervals during a Valsalva maneuver 个BRS

Review

$\downarrow$ SNS activity

$\downarrow P N S$ activity

Spectral analysis of HRV $\mathrm{BRS}$ via the sequences method $100 \%$ training load reverse effects: $\uparrow L F, \downarrow H F, B R S \downarrow$

$B R S$ via the alpha index $\leftrightarrow \mathrm{BRS}$ 


\section{TABLE III. Articles on the long-term autonomic effects of regular exercise - continued}

\begin{tabular}{|c|c|c|c|}
\hline 35 & Nagai et al. & $\begin{array}{l}\text { Moderate physical exercise increases } \\
\text { cardiac ANS activity in children with low HRV }\end{array}$ & $\begin{array}{l}\text { Spectral analysis of HRV } \\
\uparrow L F, \downarrow H F\end{array}$ \\
\hline 38 & Pigozzi et al. & $\begin{array}{l}\text { Effects of aerobic exercise training on } 24 \mathrm{hr} \\
\text { profile of HRV in female athletes }\end{array}$ & $\begin{array}{l}\text { Time domain and spectral } \\
\text { analysis of HRV } \\
\leftrightarrow \text { Time domain } \\
\leftrightarrow L F, H F \text { (daytime) }\end{array}$ \\
\hline 20 & Gulli et al. & $\begin{array}{l}\text { Moderate aerobic training improves } \\
\text { autonomic CV control in older women }\end{array}$ & $\begin{array}{l}\text { Spectral analysis of HRV and BPV } \\
\text { 个BRS } \\
\text { 个LF (RR), LF (SAP) }\end{array}$ \\
\hline 18 & Goldsmith et al. & $\begin{array}{l}\text { Comparison of } 24 \text {-hour parasympathetic } \\
\text { activity in endurance-trained and } \\
\text { untrained young men }\end{array}$ & $\begin{array}{l}\text { Report conflicting results } \\
\text { Spectral analysis of HRV } \\
\uparrow H F\end{array}$ \\
\hline 21 & Hautala et al. & $\begin{array}{l}\text { Cardiovascular autonomic function correlates } \\
\text { with the response to aerobic training in } \\
\text { healthy sedentary subjects }\end{array}$ & $\begin{array}{l}\text { Baseline vagal (HF) influences } \\
\text { determines effect of exercise training }\end{array}$ \\
\hline
\end{tabular}

LF = low frequency; HFR = high frequency; SDN = standard deviation of all intervals; Ptot = total frequency power; pNN50 = percentage of successive interval differences greater than $50 \mathrm{ms;}$ SNS = sympathetic nervous system; PNS = parasympathetic nervous system; SAP = systolic arterial pressure

\section{TABLE IV. Possible confounding factors}

Inter-individual variation

Baseline cardiovascular autonomic function

Age

Gender

Fitness

$\mathrm{BMI}$

Diet

Alcohol consumption

Smoking

Analysis techniques

Time and frequency domain measures do not describe

non-linear features in HR behaviour

Use of DA, ApEn

Length of sampling time (tachogram)

Training/exercise

Length of training period

Intensity of training

Type of exercise: resistance or endurance

did not alter compared with significantly reduced total power found after resistance exercise. However, the LF/HF ratio was significantly increased after both resistance and endurance exercise, indicating increased SNS (LF) and/or decreased PNS (HF) influence. ${ }^{24}$ This corresponds with results published by Terziotti et al., who found a reduced HF (vagal) component of HR and decreased BRS during 15 minutes of recovery. ${ }^{49}$ Another study ${ }^{22}$ also found suppressed vagal (HF) activities 10 minutes of recovery after $100 \%$ of the individual ventilatory threshold compared with baseline values. Raczak et al. found no differences in HF and LF activities between pre- and post-exercise measurements, but increased BRS and overall HRV as measured by standard deviation of all intervals (SDNN) after exercise. ${ }^{40}$ However, Kamath et al. ${ }^{26}$ and Figueroa et al. ${ }^{15}$ reported significant increased LF power during post-exercise recovery. This contrasts with findings by Arai et al., who reported significantly decreased HR power at all frequencies compared with baseline values in normal subjects. ${ }^{3}$ Decreased BRS and HRV after exercise were also reported in other studies. ${ }^{9,23}$ Lucini et al. reported that ageing progressively reduces the cardiac autonomic excitatory response to light exercise. ${ }^{28}$

Articles on the effect of an endurance training programme over a period of time also showed a wide range of results. One study ${ }^{15}$ reported no change in baseline BRS and HRV values after a 16week fitness programme, while another found increased BRS when comparing fitness levels. ${ }^{47}$ Aubert et al. also found no evidence of significant changes in resting autonomic modulation of the sinus node after a low-volume, moderate-intensity 1year exercise programme. ${ }^{4}$ Comparing 11 young sedentary participants and 10 endurance-trained cyclists Martinelli et al. found no difference in power-spectral components of HRV at rest. ${ }^{31}$ However, a lower HR and higher values for time domain HRV indicators were reported during rest and head-up tilt, concluding that resting bradycardia seems to be more related to changes in intrinsic mechanisms than to ANS control modifications. Sharma et al. found no statistically significant changes in autonomic cardiovascular control measured by HRV after a physical training programme of 15 days. ${ }^{45}$ Perini and Veicsteinas ${ }^{37}$ reported no influence of factors such as age and fitness level, while Bucheit and Gindre ${ }^{10}$ showed that modifications in autonomic activities induced by training are visible in HRV power spectra at rest. Rackzak et al. ${ }^{39}$ reported PNS dominance by measuring HRV and increased BRS after long-term exercise training. Another study ${ }^{36}$ reported increased HRV and BRS in Masters Athletes compared with decreased values for sedentary seniors. Several other studies also concluded that regular physical activity increases vagal influence on the $\mathrm{HR}$ and $\mathrm{BRS}$, while the sympathetic tone may be decreased. $8,11-13,17,19,25,27,32,34$ However, lellamo et al. ${ }^{25}$ found a reversal of these effects after a period of training at $100 \%$ training load. Very intensive training shifted the CV autonomic modulation from PNS toward SNS predominance. Increases were reported in all components of HRV after a 1-year exercise training programme in children who initially had low HRV. ${ }^{35}$ In 2001 Pigozzi et al. ${ }^{38}$ found that a 5 -week exercise training period in female athletes increased the SNS cardiac modulation, which may coexist with relatively reduced or unaffected vagal modulation. Gulli et al. ${ }^{20}$ reported increased LF reactivity (SNS) and BRS after a moderate aerobic training programme in older women.

In 1992 Goldsmith et al. ${ }^{18}$ noted that, although exercise training may increase PNS activity, studies report conflicting results. As seen from the above summary, nearly two decades later conflicting results persist when the effects of exercise training on the ANS is measured during exercise, directly after exercise and after a long-term exercise programme. Possible confounding factors mentioned and identified are listed in Table IV.

A possible explanation for conflicting results is that the individual's response is greatly influenced by the baseline cardiovascular autonomic function, thus producing large inter-subject variation in the 
conventional non-spectral and spectral measures of cardiovascular variability. Hautala et al. $^{21}$ suggested that high vagal activity at baseline is associated with improvement in aerobic power caused by aerobic exercise training. We also observed that some studies used non-homogeneous participant groups with regard to age, gender and BMI, while others did not include these in the participant description. Factors often not taken into consideration are baseline blood pressure, blood cholesterol and diet. The effect of duration and intensity of the training programme as well as the type of exercise (endurance or resistance) may have been underestimated in studies on the ANS and exercise. ${ }^{24}$ In this review training periods from 15 days to 1 year were studied and the different degrees of exercise intensity used were not even mentioned in many articles. ${ }^{22}$ The choice and specific analysis techniques implemented may also play a role in the observed conflicting results. The recommended sampling time (tachogram) for HRV analysis is 5 minutes, ${ }^{48}$ but different time windows were selected by different authors -5 minutes, 10 minutes, 15 minutes and 24 hours. The articles studied used mostly traditional measures of variability, such as time and frequency. However, it is known that non-linear phenomena are involved in cardiovascular control. Therefore, the use of analysis techniques that acknowledge this fact should be co-implemented and reported with traditional measures. Examples include the measurement of fractal scaling exponents (describes the fractal-like correlation properties of R-R interval data) and ApEn (quantifies the amount of complexity in the time series data). ${ }^{30}$

\section{Conclusions}

This review demonstrates the wide variety of results published during the past decades on the effect of training on the ANS as measured by cardiovascular variability indicators. It is clear from the results that standardisation and refinement of these measuring tools are essential to produce repeatable results that can be used as references in other studies. This is necessary as these measurements are increasingly employed in studies ranging from investigations of central autonomic regulation; to studies exploring the link between psychological processes and physiological functioning; to the indication of ANS activity in response to exercise, training and overtraining. Important aspects to consider when developing standardised procedures are inter-individual differences, duration and intensity of the exercise programme, and the choice and implementation of a specific variability analysis technique. Much more research needs to be done to fully describe and accurately quantify the effect of exercise on the ANS.

\section{REFERENCES}

1. Akselrod S, Gordon D, Ubel FA, Shannon DC, Berger AC, Cohen RJ Power spectrum analysis of heart rate fluctuation: a quantitative probe of beat-beat cardiovascular control. Science 1981; 213: 220-222.

2. AL-ANI M, Munir SM, White M, Towend J, Coote JH. Change in R-R variability before and after endurance training measured by power spectral analysis and by the effect of isometric muscle contraction. Eur J Appl Phys 1996; 74: 397-403

3. Arai $\mathrm{Y}$, Saul JP, Albrecht $\mathrm{P}$, et al. Modulation of cardiac autonomic activity during and immediately after exercise. Am J Phys 1989; 256: H132-141.

4. Aubert AE, Vanhees L, Beckers F, Eijnde BO, Verheyden B. Low-dose exercise training does not influence cardiac autonomic control in healthy sedentary men aged 55-75 years. J Sports Sci 2006; 24(11): 11371147.

5. Banach T, Grandys M, Juszczak K, et al. Heart rate variability during incremental cycling exercise in healthy untrained young men. Folica Medica Cracovensia 2004; 45(1-2): 3-12.
6. Bertinieri G, di Rienzo M, Cavallazzi A, Ferrari AU, Pedotti A, Mancia G. A new approach to analysis of the arterial baroreflex. J Hypertens (Suppl) 1985; 3(3): S79-S81.

7. Boutcher $\mathrm{SH}$, Stein P. Association between heart rate variability and training response in middle-aged men. Eur J Appl Phys 1995; 70: 75-80.

8. Bowman AJ, Clayton RH, Murray A, Reed JW, Subhan MMF, Ford GA. Effects of aerobic exercise training and yoga on the baroreflex in healthy elderly persons. Eur J Clin Invest 1997; 27(5): 443-449.

9. Brown SJ, Brown JA. Resting and post-exercise cardiac autonomic control in trained master athletes. J Physiol Sci 2007; 57(1): 23-29.

10. Buchheit M, Gindre C. Cardiac parasympathetic regulation: respective associations with cardiorespiratory fitness and training load. Am J PhysHeart Circulatory Phys 2006; 291(1): 451-458.

11. Carter JB, Banister EW, Blaber AP. Effect of endurance exercise on autonomic control of heart rate. Sports Med 2003; 33(1): 33-46.

12. Cooke WH, Reynolds BV, Yandl MG. Effects of exercise training on cardiovagal and sympathetic response to Valsalva's maneuver. Med Sci Sports Exer 2002; 34(6): 928-935.

13. Costes F, Roche F, Pichot V, Vergnon JM, Garet M, Barthelemy JC. Influence of exercise training on cardiac baroreflex sensitivity in patients with COPD. Eur Respir J 2004; 23(3): 396-401.

14. Eryonucu B, Bilge M, Guler N, Uygan I. The effect of autonomic nervous system activity on exaggerated blood pressure response to exercise: evaluation by heart rate variability. Acta Cardiologica 2000; 55(3): 181185.

15. Figueroa A, Baynard T, Fernhall B, Carhart R, Kanaley JA. Endurance training improves post-exercise cardiac autonomic modulation in obese women with and without type 2 diabetes. Eur J Appl Physics 2007; 100: 437-444.

16. Freeman JV, Dewey FE, Hadley DM, Myers D, Froelicher V. Autonomic nervous system interaction with the cardiovascular system during exercise. Prog Cardiovasc Dis 2006; 48(5): 342-362.

17. Goldsmith RL, Bigger JT Jr, Bloomfield DM, Steinman RC. Physical fitness as a determinant of vagal modulation. Med Sci Sports Exerc 1997; 29(6): 812-817.

18. Goldsmith RL, Bigger JT Jr, Steinman RC, Fleiss JL. Comparison of 24hour parasympathetic activity in endurance-trained and untrained young men. J Am Coll Cardiol 1992; 20(3): 552-558.

19. Goldsmith RL, Bloomfield DM, Rosenwinkel ET. Exercise and autonomic function. Coron Artery Dis 2000; 11(2): 129-135.

20. Gulli G, Cevese A, Cappelletto P, Gasparini G, Schena F. Moderate aerobic training improves autonomic cardiovascular control in older women. Clin Auton Res 2003; 13(3): 196-222.

21. Hautala AJ, Makikallio TH, Kiviniemi A. Cardiovascular autonomic function correlates with the response to aerobic training in healthy sedentary subjects. Am J Phys-Heart Circulatory Phys 2003; 285(4): 52-60.

22. Hayashi N, Nakamura Y, Muraoka I. Cardiac autonomic regulation after moderate and exhaustive exercises. Ann Phys Anthropology 1992; 11(3): 333-338

23. Heffeman KS, Collier SR, Kelly EE, Jae SY, Fernhall B. Arterial stiffness and baroreflex sensitivity following bouts of aerobic and resistance exercise. Int J Sports Med 2007; 28: 197-203.

24. Heffernan KS, Kelly EE, Collier SR, Fernhall B. Cardiac autonomic modulation during recovery from acute endurance versus resistance exercise. Eur J Cardiovascular Prevention and Rehabilitation 2006; 13(1): 80-86.

25. Iellamo F, Legramante JM, Pigozzi F, et al. Conversion from vagal to sympathetic predominance with strenuous training in high-performance world class athletes. Circulation 2002; 105(23): 2719-2724

26. Kamath MV, Fallen EL, McKelvie R. Effects of steady state exercise on the power spectrum of heart rate variability. Med Sci Sports Exer 1991; 23(4): 428-434.

27. Kiviniemi AM, Hautala AM, Makikallio TH, Huikuri HV, Tulppo MP. Cardiac vagal outflow after aerobic training by analysis of high-frequency oscillation of the R-R interval. Eur J Appl Phys 2006; 96(6): 686-692.

28. Lucini D, Cerchiello M, Pagani M. Selective reductions of cardiac autonomic responses to light bicycle exercise with aging in healthy humans. Autneu 2004; 110(1): 55-63.

29. Lucini D, Trabucchi V, Malliani A, Pagani M. Analysis of initial autonomic adjustments to moderate exercise in humans. J Hypertens 1995; 13(12): 1660-1663.

30. Lyengar N, Peng CK, Morin R, Goldberger AL, Lipsitz LA. Age-related alterations in the fractal scaling of cardiac interbeat interval dynamics. Am J Physiol Regulatory Integrative Comp Physiol 1996; 271: 1078-1084. 
31. Martinelli FS, Chacon-Mikahil MPT, Martins LEB, Lima-Filho R, Paschoal MA, Gallo L. Heart rate variability in athletes and non-athletes at rest and during head-up tilt. Braz J Med Bio Res 2005; 38(4): 639-647.

32. Melo RC, Santos MD, Silva E, et al. Effects of age and physical activity on the autonomic control of heart rate in healthy men. Braz $\mathrm{J}$ Med Bio Res 2005; 38(9): 1331-1338

33. Michalsen A, Dobos GJ. Heart rate reduction through lifestyle modification. Eur Heart J 2005; 26(7): 1806-1807.

34. Monahan KD, DInenno FA, Tanaka H. Regular exercise modulates ageassociated declines in cardiovagal baroreflex sensitivity in healthy men. $J$ Phys 2000; 529(1): 263-271.

35. Nagai N, Hamada T, Kimura T, Moritani T. Moderate physical exercise increases cardiac autonomic nervous system activity in children with low heart rate variability. Childs Nerv Sys 2004; 20(4): 215-200.

36. Okazaki K, Iwasakl K, Prasad A, et al. Dose-response relationship of endurance training for autonomic circulatory control in healthy seniors. $J$ Appl Phys 2005; 99(3): 1041-1049.

37. Perini $R$, Veicsteinas $A$. Heart rate variability and autonomic activity at rest and during exercise in various physiological conditions. Eur J Appl Phys 2003; 90(3-4): 317-325.

38. Pigozzi F, Alabiso A, Parisi . Effects of aerobic exercise training on $24 \mathrm{hr}$ profile of heart rate variability in female athletes. J Sports Med Phys Fitness 2001; 41(1): 101-107.

39. Raczak G, Danilowicz-Szymanowicz L, Kobuszewska-Chwirot M Ratkowski W, Figura-Chmielewska M, Szwoch M. Long-term exercise training improves autonomic nervous system profile in professional runners. Kardiologia Polska 2006; 64(2): 135-140, 141-142 (discussion).

40. Raczak G, Pinna GD, La Rovere MT, et al. Cardiovagal response to acute mild exercise in young healthy subjects. Circ J 2005; 69(8): 976-980.

41. Sacknoff DM, Gleim GW, Stachenfield N, Coplan NL. Effect of athletic training on heart rate variability. Am Heart J 127: 1275-1278.

42. Saito M, Nakamura Y. Cardiac autonomic control and muscle sympathetic nerve activity during dynamic exercise. Jpn J Phys 1995; 45(6): 961-977.
43. Sandercock GR, Brodie DA, Sandercock GRH. The use of heart rate variability measures to assess autonomic control during exercise. Scand J Med Sci Sports 2006; 16(5): 302-313.

44. Schachinger H, Weinhaber M, Kiss A, Ritz R, Langewitz W. Cardiovascular indices of peripheral and central sympathetic activation. Psychosom Med 2001; 63: 788-796.

45. Sharma RK, Deepak KK, Bijlani RL, Rao PS. Short-term physical training alters cardiovascular autonomic response amplitude and latencies. Indian J Physiol Pharmacol 2004; 48(2): 165-173.

46. Shin K, Minamitani H, Onishi S, Yamazakih, Lee M. Autonomic differences between nonathletes: spectral analysis approach. Med Sci Sports Exer 1997; 29: 482-1490.

47. Spierer DK, DeMeersman RE, Kleinveld J, et al. Exercise training improves cardiovascular and autonomic profiles in HIV. Clin J Auton Res 2007; 17: 341-348.

48. Task Force of the European Society of Cardiology and the North American Society of Pacing and Electrophysiology. Heart rate variability: standards of measurement, physiology interpretation and clinical use. Circulation 2006; 93: 1043-1065.

49. Terziotti P, Schena F, Gulli G, Cevese A. Post-exercise recovery of autonomic cardiovascular control: a study by spectrum and cross-spectrum analysis in humans. Eur J Appl Phys 2001; 84(3): 187-194.

50. Yamamoto K, Miyachi M, Saitoh T, Yoshioka A, Onodera S. Effects of endurance training on resting and post-exercise cardiac autonomic control. Med Sci Sports Exerc 2001; 33(9): 1496-1502.

51. Yamamoto $\mathrm{Y}$, Hughson RL, Peterson JC. Autonomic control of heart rate during exercise studied by heart rate variability spectral analysis. $J$ Appl Phys 1991; 71(3): 1136-1142.

52. Zhang R, Iwasaki K, Zuckerman JH, Behbehani K, Crandall CG, Levine $\mathrm{BD}$. Mechanism of blood pressure and R-R variability: insights from ganglion blockade in humans. J Phys 2002; 543: 337-348. 